Foot Ankle Int. 2018 September ; 39(9): 1028-1038. doi:10.1177/1071100718776021.

\title{
Frequency and impact of adverse events in patients undergoing surgery for end stage ankle arthritis
}

\author{
Daniel C. Norvell, Ph.D. ${ }^{1}$, Jane B. Shofer, M.S. ${ }^{2}$, Sigvard T. Hansen, M.D. ${ }^{3}$, James Davitt, \\ M.D. ${ }^{5}$, John G. Anderson, M.D. ${ }^{4}$, Donald Bohay, M.D. ${ }^{4}$, J. Chris Coetzee, M.D. ${ }^{6}$, John \\ Maskill, M.D. ${ }^{4}$, Michael Brage, M.D. ${ }^{3}$, Michael Houghton, M.D. ${ }^{7}$, William R. Ledoux, Ph.D. \\ 2,3,8, and Bruce J. Sangeorzan, M.D. ${ }^{2,3}$ \\ ${ }^{1}$ Spectrum Research, Tacoma, WA \\ ${ }^{2}$ VA Puget Sound Health Care System, Seattle, WA \\ ${ }^{3}$ Department of Orthopaedics and Sports Medicine, University of Washington, Seattle, WA \\ ${ }^{4}$ Orthopaedic Associates of Michigan, Grand Rapids, MI. \\ ${ }^{5}$ Orthopedic + Fracture Specialists, Portland, OR. \\ ${ }^{6}$ Twin Cities Orthopedics, Edina, MN. \\ ${ }^{7}$ Orthopaedic \& Spine Center of the Rockies, Fort Collins, CO. \\ ${ }^{8}$ Department of Mechanical Engineering, University of Washington, Seattle, WA
}

\begin{abstract}
Background-This study summarized the frequency and functional impact of adverse events (AEs) that occur after surgery for End-stage ankle arthritis (ESAA) to inform decision making.

Methods-This was a multi-site prospective cohort study to compare ankle arthroplasty to ankle arthrodesis in the treatment of ESAA among six participating sites. We compared the risk and impact of non-ankle AEs and ankle-specific AEs versus no AEs controlling for potential confounding factors including surgical procedure using multinomial logistic regression. We estimated differences in post-op functional outcomes by AE occurrence using linear mixed effects regression. Among 517 patients who had surgery for ankle arthritis and completed the full baseline assessment, follow up scores were available in 494 (95\%) patients.
\end{abstract}

\begin{abstract}
Results-There were a total of 628 reported AEs (477 in the arthroplasty group and 151 in the arthrodesis group). These occurred in 261 (63\%) arthroplasty patients and 67 (65\%) arthrodesis patients. There were $50(8 \%)$ ankle specific AEs. The risk of an ankle specific AE was slightly higher in the arthrodesis group vs the arthroplasty group, odds ratio $1.84,95 \% \mathrm{CI}(.85,3.98)$. The odds ratio for the risk of non-ankle specific $\mathrm{AE}$ versus no $\mathrm{AE}$ was $.96,95 \% \mathrm{CI}(.57,1.61)$ for those receiving arthrodesis compared to arthroplasty. Compared to patients with no AEs, those experiencing ankle-specific AEs had significantly less improvement in Foot and Ankle Ability
\end{abstract}

Level of Evidence

Level II - Prospective Comparative Study 
Measure Sports and ADL subscores and worst pain outcomes; however, both groups improved significantly in all measures except mental health.

Conclusions-Ankle specific AEs were infrequent and only weakly associated with surgical procedure. While patients improved in all functional outcomes except mental health, regardless of AE occurrence, ankle-specific AEs negatively impacted patient improvement compared to those with no AEs or a non-ankle AE. The logistical effort and cost of tracking non-ankle AEs does not seem to be justified.

\section{Keywords}

Adverse Events; Ankle Arthritis; Clinical Outcomes; Ankle Replacement; Ankle Arthrodesis; Complications

\section{INTRODUCTION}

End-stage ankle arthritis (ESAA) is a debilitating condition associated with pain, dysfunction, and reduced quality of life. ${ }^{9}$ Ankle arthritis affects approximately $6 \%$ of the population, ${ }^{16}$ and data from the Health Care Utilization Project online indicate that hospital charges for the treatment of ankle arthritis exceed $\$ 370$ million per year. ${ }^{8,12,16}$ Patients seeking surgical treatment for ESAA have two primary treatment options: arthrodesis and arthroplasty. While there are multiple comparative trials that address these two treatment options, neither the complication risk or the relative effectiveness is clearly established. $5,21,26,29,30$

Adverse events (AE) in orthopedics may have a negative impact on medical care, increase costs and reduce the effectiveness of treatment. ${ }^{28}$ Rates of AEs in ankle arthritis are not clear. ${ }^{27}$ Millstone et al demonstrated the effectiveness of point of care reporting for AEs and the ability to link AEs to specific risk factors, anatomic regions and procedures. ${ }^{28}$ Other areas of orthopedics have made inroads into capturing the impact of AEs. The Knee Society created a list of 22 complications out of all potential AEs that have a negative impact on patients. ${ }^{14}$ Similarly, factors that have a negative impact on ankle fractures have been identified. ${ }^{37} \mathrm{~A}$ coding system specific to increasing severity of reoperation for ankle surgery has also been reported. ${ }^{40}$ Others have concurred that there is utility in severity weighted $\mathrm{AE}$ reporting. ${ }^{4}$

While treatment specific AEs may not be rigorously collected in routine observational studies, sponsored clinical studies require extensive AE reporting. According to the International Conference on Harmonisation of Technical Requirements for Registration of Pharmaceuticals for Human Use (ICH), an Adverse Event is "any untoward medical occurrence in a patient or clinical investigation subject administered a pharmaceutical product and which does not necessarily have to have a causal relationship with this treatment". These standards are required for clinical trials, ${ }^{13}$ adding considerable administrative and cost burden to clinical trials even when no pharmaceutical product is involved. The value added for surgical trials where the AEs are more likely to be confined to the musculoskeletal system is unclear. The current study was monitored by a data safety 
monitoring board (DSMB) that required the collection of all AEs from all body systems whether they were related to the surgery or the study.

The focus of this study was to gain a broader understanding of the magnitude of all AEs in the perioperative and early healing period after ankle surgery and evaluate the impact of these AEs on patient functional outcomes. Our focus was on the comparative short-term safety of the two treatments rather than the comparative effectiveness. The latter results will be reported in future manuscripts. The objectives were to: (1) summarize the total number of AEs (ankle and non-ankle) in patients undergoing ankle arthroplasty and ankle arthrodesis, (2) evaluate AE risk comparing ankle arthroplasty to ankle arthrodesis, and (3) evaluate the impact of ankle and non-ankle AEs on patient reported 12 month post-op functional outcomes.

\section{METHODS}

\section{Study design}

This was a multi-site prospective cohort study to compare ankle arthroplasty to ankle arthrodesis in the treatment of ESAA. There were six participating sites. Recruitment began in May 2012 and was completed in May 2015, with multiyear follow-up continuing on an annual basis. The goal of this ongoing study is to follow patients for up to 10 years or longer. The study was conducted in accordance with the procedures approved by human subjects review boards at each participating institution.

\section{Participants}

All participants presenting for surgical treatment for ankle arthritis meeting the following inclusion criteria were approached for participation: adult patients between 21 and 89 years of age, ambulatory but whose primary impediment to pain-free ambulation was ankle arthritis, and a telephone number and stable mailing address. Patients were excluded if they met the following criteria: recent surgical, neurological, metabolic, or lower limb musculoskeletal problem such as severe knee or hip OA, planned complicated foot and ankle procedure requiring multiple corrections, inflammatory arthritis with multi-focal disease (i.e., arthritis that affects multiple parts of the body), known diabetes requiring treatment, inadequate cognitive or language function to consent to participate, or unable or unwilling to participate in follow-ups. Eight hundred and twelve consecutive patients were screened for participation. Among these, 161 (20\%) did not meet study criteria and 95 (12\%) were unwilling to participate, leaving 556 who consented to participate. Thirty four of these were unable to undergo surgery and therefore withdrawn from the study leaving 522 who consented and underwent either arthrodesis or arthroplasty based on surgeon and patient preference and discussion.

\section{Baseline characteristics}

The following baseline risk factors were collected through interview and supplemented by the medical record (including X-rays/CT scans) sometime prior to or immediately after surgery: demographic factors (i.e., gender, age, body mass index (BMI), race, marital status, education level, employment status, and income); ankle factors (i.e., cause of ESAA, 
previous ankle surgeries, degrees of subluxation, and severity of OA using the KellgrenLawrence Grading Scale); ${ }^{18}$ comorbidities using the Functional Comorbidity Index (FCI) ${ }^{11}$ (0-18 point scale with higher scores representing greater comorbidity), and consumption history (i.e., smoking and alcohol use).

Among the 522 participants who consented and had surgery, 419 underwent arthroplasty and 103 underwent arthrodesis. Five withdrew immediately after surgery leaving 517 who completed the full baseline assessment. (These patients were consented and had surgery but decided after completing the pre-surgical assessment that they did not have time for a follow-up study and asked to be withdrawn. The dropout occurred before any post treatment outcome measures were collected.) Baseline and follow up scores were available in 493 (95\%) patients, (395 (95\%) in the arthroplasty group and 98 (95\%) in the arthrodesis group) (Figure 1). Concerning baseline characteristics, the two groups were not significantly different with regards to sex, race, marital status, education, severity of OA, alignment, and alcohol use (Table 1). Patients who received arthroplasty were older, lighter, were less likely to be employed, less likely to have had a previous ankle surgery, and had lower functional comorbidity scores. All these differences were evaluated as potential confounders and included in the regression analyses if they met the a priori criteria.

\section{Adverse events, revisions and major complications}

Because this was an NIH funded study with a DSMB assigned, we were required to collect and classify all AEs from all body systems. The DSMB then determined the relationship to the study. The majority of reported AEs were unrelated to the surgery or the study. For this study, we defined an AE occurrence within 12 months of surgery as "none", "non-ankle specific"(such as urinary tract infection), or "ankle-specific". Ankle-specific AEs were further classified in the following manner: (1) major revisions defined as reoperation requiring non weight bearing, (2) minor revisions defined as reoperation not requiring non weight bearing and (3) minor AEs that did not require a reoperation such as cellulitis, intraoperative fracture, and tarsal tunnel syndrome.

\section{Patient Reported Functional Outcomes}

All patient-reported functional outcomes were assessed at baseline and at 12 month followup. We measured ankle specific function using the Foot and Ankle Ability Measure (FAAM). The FAAM measures several functional categories, is easily scored, and has been validated against the SF-36 physical function subscale. ${ }^{25}$ All FAAM subscale scores are standardized on a $0-100 \%$ scale with the higher percentage representing greater function. The FAAM has an established MCID of 9 points ${ }^{20}$ and provides a wide range of functional ability items including a higher ceiling SPORTS (SPT) subscore and an activities of daily living (ADL) subscore. Pain was assessed using two questions from the Chronic Pain Grade (CPG), including intensity of present ankle pain and intensity of worst ankle pain in past 6 months. The CPG has a simple and brief format, and it demonstrates good internal consistency and reliability. ${ }^{17,39}$ The SF-36 Physical Component Summary (PCS) and Mental Component Summary (MCS) scores were also obtained (0-100 point scale for both). 


\section{X-rays}

The subjects had weight bearing X-rays taken of their ankle throughout the course of their clinical care based on clinical need. Any radiographic concerns identified by clincians were logged by study coordinators. Pre-surgical X-rays were required to determine the baseline degree and severity of ESAA.

\section{Surgical procedures}

The arthroplasty and arthrodesis procedures, devices, and postoperative rehabilitation protocols were consistent with the standard of care. Both procedures were performed by all surgeons. All participating surgeons were trained in hip, knee and ankle arthroplasty, had at least 5 years of experience and had performed at least 30 arthroplasty and 30 arthrodesis procedures to avoid errors related to surgical inexperience. Arthroplasty protocols were similar among participating centers. Each surgeon used the clinically appropriate surgical approach, splinted the ankles for 2-3 weeks, and restricted weight bearing for the first 3-6 weeks. For arthrodesis, a well-established technique of rigid internal fixation was implemented. Patients were allowed to walk with weight bearing aids immediately. Weight bearing was allowed on the limb in increments over the 3 to 12 weeks after surgery. Decisions for weight bearing for both techniques were guided by radiographs.

\section{Statistical analysis}

Differences in categorical variables between treatment groups were assessed using the Chisquare test. Differences in continuous variables were assessed using a two sample t-test. We performed a rigorous evaluation of all potential confounders. Baseline variables that were unequally distributed between surgical procedure groups were identified, based on a $P<.10$. We considered a priori whether these variables would have an important effect on the outcomes of interest (adverse events and patient reported functional outcomes) based on literature support and clinical experience. The traditional confounders, age, sex and BMI were included as covariates in all analyses. For all other potential confounding variables, we included them in each regression analysis if they were associated with any of the outcomes of interest at $P<.10$.

For our second aim, the association between surgical procedure and risk of an AE was assessed using multinomial logistic regression with $\mathrm{AE}$ occurrence (none, non-ankle specific or ankle specific) as the dependent variable and surgical procedure as the main independent effect of interest. Odds ratios and $95 \%$ confidence intervals (CI) were estimated for ankle $\mathrm{AE}$ versus none and non-ankle AE versus none for surgical procedure in bivariable models and in multivariable models with potential confounders as covariates.

For our third aim, linear mixed effects regression was used to determine if there were differences in postoperative improvement in each primary outcome by occurrence of an $\mathrm{AE}$ (none, non-ankle specific or ankle specific). Primary outcome measures (FAAM ADL, SPT, SF36 PCS, SF35 MCS, present pain and worst pain in last six months) were the dependent variables. Study visit (baseline or post treatment), AE occurrence, surgical procedure and potential confounders, evaluated as described above, were the independent fixed main effects. All models included main effect variables by study visit interactions to estimate the 
difference in postoperative improvement by $\mathrm{AE}$ occurrence adjusting for improvement due to the potential confounders including surgical procedure. Means and $95 \%$ confidence intervals for improvement for each $\mathrm{AE}$ group and differences in improvement by ankle specific $\mathrm{AE}$ or non-ankle specific $\mathrm{AE}$ versus no $\mathrm{AE}$ were estimated using simultaneous inference $^{15}$. To determine if differences in improvement by $\mathrm{AE}$ occurrence were modified by surgical procedure, visit by AE occurrence by surgery interaction were added to the above models.

Statistical significance was set at $P<.05$. Estimated means in the text are presented \pm standard errors and/or 95\% CI. Analyses were carried using Stata 9.1 and R 3.3.2 35 with additional packages $1 \mathrm{me} 4^{1}$, multcomp $^{15}$, 1 smeans ${ }^{24}$, nnet ${ }^{36}$ and ggplot $2^{38}$.

\section{RESULTS}

\section{Total number of ankle and non-ankle AEs comparing the two surgical procedures}

There were a total of 628 reported AEs, 477 in the arthroplasty group and 151 in the arthrodesis group (Figure 2). These occurred in 261 (63\%) arthroplasty patients and 67 (65\%) arthrodesis patients. These AEs varied across all body systems and the majority were not serious or related to the ankle surgery but were required for reporting purposes. There were 50 ankle specific complications: 33 (8\%) arthroplasty and $17(17 \%)$ arthrodesis. This represents only $8 \%$ of the total number of AEs collected. There were 7 and 4 major revisions, 9 and 9 minor revisions, and 17 and 4 minor AEs, in the arthroplasty and arthrodesis groups, respectively. Due to the low event rate in each of the sub-categories, we combined all ankle-specific AEs into one category for the analyses of ankle-specific AEs.

\section{Risks of adverse event occurrence comparing arthroplasty to arthrodesis}

Based on our evaluation of potential confounders, we selected age, BMI, sex, and FCI as baseline risk factors for AE occurrence. Odds ratios are presented. An odds ratio (OR) is a measure of association between an exposure-in this case a surgery type or a demographic difference - and an outcome, in this case an adverse event. The OR represents the odds that an outcome will occur given a particular exposure, compared to the odds of the outcome occurring in the absence of that exposure.

From the bivariable multinomial logistic regression, the odds ratio for the risk of an ankle specific $\mathrm{AE}$ and for a non-ankle $\mathrm{AE}$ versus no $\mathrm{AE}$ was $2.23,95 \% \mathrm{CI}(1.12,4.44)$ and .96 , $95 \% \mathrm{CI}(.60,1.55)$, respectively, for those receiving arthrodesis compared to arthroplasty (omnibus test for the association between AE occurrence and surgery type $P=.05$ ). In other words, there was an increase in risk for an ankle specific adverse event in the arthrodesis group relative to the ankle replacement group but no increased risk in the non ankle specific $\mathrm{AE}$ in one group vs the other. In a multiple multinomial logistic regression of $\mathrm{AE}$ occurrence with covariates age, sex, BMI, FCI and surgical procedure, the OR for risk of an ankle AE vs. no AE for arthrodesis compared to arthroplasty was attenuated from the bivariable model to $1.84,95 \% \mathrm{CI}(0.85,3.98)$, while the OR for a non-ankle AE vs. no AE remained the same $(.96,95 \% \mathrm{CI}(.57,1.61)$, omnibus test for the association between AE occurrence and surgery type $P=.23)$. 


\section{Independent effects AE on outcomes controlling for surgical procedure}

Based on our evaluation of potential confounders, all models included main effects and interactions with study visit for age, sex, BMI, FCI, and surgical procedure. There was no difference in mean improvement between patients experiencing non-ankle specific AEs compared to those who had no AEs in all patient reported outcomes (Table 2, $P \geq 80$ ). Both of these groups experienced significant mean improvement in all outcome measures except for an only minimal improvement in the SF36 MCS scale in those with no AE. Compared to patients with no AEs, those experiencing ankle-specific AEs had significantly less improvement in FAAM ADL, SPT and worst pain in the past 6 months by 13 points, $95 \%$ CI $(5,21) ; 17$ points, $95 \% \mathrm{CI}(5,28)$ and 1.7 points, $95 \% \mathrm{CI}(0.5,2.9)$, respectively. Those experiencing an ankle-specific AE improved less in SF36 PCS scores by 3.6 points, $95 \%$ CI $(-0.3,7.4)$, but this did not quite reach statistical significance $(\mathrm{P}=.06)$. Despite these differences in improvement between those with an ankle $\mathrm{AE}$ versus those with no $\mathrm{AE}$, those experiencing an ankle AE still had significant improvements in all outcomes except the SF36 MCS.

There was no evidence that surgical procedure modified the effect of AE status on any outcome (visit by surgery by AE occurrence interaction $P>.36$ ) except for the SPORTS subscore where 12 month improvement for those receiving arthrodesis who had an ankle specific $\mathrm{AE}$ was flatter (i.e., no improvement) than expected given the additive independent effects of surgery type and AE occurrence. However the visit by surgery by AE occurrence interaction was not significant, $(P=.09)$. Summary panel plots for the improvement in FAAM, ADL, and SPT scores by surgical procedure and AE occurrence are presented (Figures $3 \mathrm{a}$ and $3 \mathrm{~b}$ ). Panel plots for all other outcomes are included in the Supplemental Data (Figures S1a to S1d).

\section{DISCUSSION}

The study had three primary goals. To summarize the total number of AEs (ankle and nonankle) during the first year after surgery in patients undergoing ankle arthroplasty and ankle arthrodesis, to evaluate AE risk comparing these two procedures, and to evaluate the impact of ankle and non-ankle AEs on patient reported functional outcomes.

There is growing evidence that we do not have adequate data to assess the impact of AEs in orthopedics. ${ }^{23,33}$ The impact of AEs on outcomes is clouded by inconsistent or unclear reporting of AEs and lack of direct linking of AE to consequences. ${ }^{10,22,27,40}$ AEs are uncommon in orthopedics but increase costs and negatively impact outcomes. ${ }^{7}$ Millstone et al. identified the likelihood of under reporting AEs in orthopedic procedures when using administrative databases and instead identified AEs at the point of care. ${ }^{28}$ They used a reporting system with common definitions and a standardized capture system to record AEs in orthopedic surgical care of the hip, knee and spine. AEs were captured if they caused patient harm or required additional monitoring or treatment. They were able to identify different event rates in different surgical procedures and to identify predictors of AEs. The $\mathrm{AE}$ event rate for degenerative conditions of the knee was $27 \%$ and for the hip $25 \%$. They stratified the severity of the events but did not attempt to estimate the impact of an AE on pain or other self-reported outcomes. The majority of the AEs (90\%) were in the immediate 
post-operative period. Only $7 \%$ were intra-operative and 3\% were in both intra and postoperative periods.

Comparing outcomes from different treatments of ankle arthritis is in part dependent upon understanding the impact of adverse events. Younger et al suggested that we track not only the event rate of complications but the nature and intensity of those complications in order to determine the value of surgical treatment of ankle arthritis. ${ }^{40}$ The authors created a system with 11 codes representing causes for reoperation and types of reoperation in the years following ankle replacement or fusion. The study established good inter observer agreement of the classification system. Impact of the different codes on patient reported functional outcomes was not addressed.

Krause et al tracked the complications in 114 ankle replacement and 43 ankle arthrodesis patients who were followed for a minimum of 2 years after surgery using the AOS . ${ }^{22}$ Fifty four percent of the patients who had an ankle replacement and $26 \%$ of the patients with an ankle arthrodesis experience an AE. Each group was adversely impacted by the complications, but there was no difference in outcome in the two groups.

The patient experience and outcome of surgical treatment of any disorder is influenced by complications of treatment. When a treatment is relatively new or infrequent, or when the surgeon is relatively inexperienced, complication rates are higher. ${ }^{31} \mathrm{~A}$ decade ago, a review of an administrative database data in California demonstrated a much higher likelihood of secondary operation in an ankle replacement cohort compared to a cohort undergoing ankle arthrodesis. ${ }^{34}$ A more recent study by Saltzman et al. demonstrated a reversal of that ratio with experienced surgeons reporting a lower risk of AEs in ankle replacement than ankle arthrodesis. ${ }^{32}$ However, the two procedures were done by two different groups of highly experienced surgeons at different institutions and procedures were not concurrent. This is similar to our observations.

The current prospective cohort study examines a large group of patients with point of care tracking of AEs by a third party data management organization and oversight by a DSMB who did not participate in the care of the patients and met standards instituted for pharmaceutical trials. There were a number of unique findings. First, the risk of any ankle specific AE was relatively low (9.6\%) with $2 \%$ of patients requiring a significant reoperation. Second, arthrodesis patients were at a higher risk of an ankle AE, but this association was attenuated and no longer statistically significant after controlling for baseline confounders. This may be the result of those undergoing fusion having higher FCI scores which were associated with experiencing and ankle-specific AE. Third, despite the occurrence of an ankle AE, these patients still had significant mean improvement in all physical and pain outcomes. However, improvement in some outcomes (FAAM ADL and SPT scores and worst pain) was less than it was for patients with no AE. Further, those undergoing arthrodesis, who experienced an ankle-specific AE, were impacted the most and improved little in the FAAM SPORTS subscore, though this interaction did not quite achieve statistical significance. The FAAM Sports subscale represents the higheset functional level. This finding may reflect the greater difficulty in achieving high level physical function after arthrodesis (versus arthroplasty), especially if an AE is experienced in the first year. Fourth, 
there was no significant difference in mean improvement between patients who did not experience an $\mathrm{AE}$ and those who experienced a non-ankle specific $\mathrm{AE}$, despite representing 92\% of all AEs. This data collection effort required a significant amount of study coordinator time and resources that could not be used for other study operations with little overall benefit. Acknowledging this, and considering focusing on ankle-specific AEs only, may free investigators from tracking all AEs in future trials. Finally, the mental health score of the SF-36 did not change significantly with surgery, in contrast to the improvement found in other measures.

This study has limitations. The primary aims were to evaluate the comparative safety of two surgical procedures and to determine the effect of AEs on patient functional outcomes. Despite a very large cohort of patients, with an overall ankle specific AE rate less than $10 \%$, it was not possible to analyze severity of AE based on our three categories of minor complication, minor revision and major revision. Therefore, we combined these. The two treatment groups were not randomized leading to an imbalance in the study groups and some baseline charcteristics. Randomization of surgical treatment for ankle arthritis has yet to be done due to the strong opinions of patients and providers on the best treatment approach. Furthermore, the AEs could not be randomized as they are naturally occurring. The observational nature of this study is subject to confounding bias when making comparisons. There is strong evidence that observational studies, if conducted with similar rigor to a clinical trial, can approximate the results of a randomized trial. The Pharmacoeconomics and Outcomes Research (ISPOR) Observational Studies (OS) Task Force published a carefully crafted statement: "It is the position of this Task Force that rigorous well designed and well executed Observational Studies can provide evidence of causal relationships". ${ }^{3}$ Several major reviews from reputable journals comparing OS to RCTs concluded that the results are similar in a large number of studies on the same topic. ${ }^{2,6,19}$ The Task force went on to conclude that if an OS is well conceived and well-performed on a relatively homogenous sample of patients, the persuasiveness of the results may be very high, especially in light of problems increasingly found in RCTs: crossover, attrition, nonadherence, and varying qualities of the participating sites and investigators, all of which serve to diminish the internal validity of the RCT. ${ }^{3}$ This study was executed with rigorous logistical and operational procedures. Each site had a designated study coordinator who tracked all patient AEs and obtained patient functional outcomes at pre-specified time points. Data was managed by a third party with routine querying and was monitored by a separate independent organization. Due to these procedures, we achieved extremely high follow-up rates exceeding 95\%. To account for baseline differences between the two surgical groups, we performed a rigorous analysis to identify all potential confounders and included them in the regression analyses. Despite this, there is still the possibility of residual confounding.

\section{Conclusion}

Ankle specific AEs were infrequent and only weakly associated with surgical procedure. While patients improved in all functional outcomes except mental health, regardless of AE occurrence, ankle-specific AEs negatively impacted patient improvement compared to those with no AEs or a non-ankle AE. The benefit of tracking non-ankle AEs does not outweigh the logistical effort and cost. 


\section{Supplementary Material}

Refer to Web version on PubMed Central for supplementary material.

\section{REFERENCES}

1. Bates D; Maechler M; Bolker B; Walker S: Fitting Linear Mixed-Effects Models Using lme4. Journal of Statistical Software. 2015; 67: 1-48.

2. Benson K; Hartz AJ: A comparison of observational studies and randomized, controlled trials. N Engl J Med. 2000; 342: 1878-1886. [PubMed: 10861324]

3. Berger ML; Dreyer N; Anderson F, et al.: Prospective observational studies to assess comparative effectiveness: the ISPOR good research practices task force report. Value Health. 2012; 15: $217-$ 230. [PubMed: 22433752]

4. Bohl DD; Ahn J; Lukasiewicz AM, et al.: Severity Weighting of Postoperative Adverse Events in Orthopedic Surgery. Am J Orthop (Belle Mead NJ). 2017; 46: E235-E243. [PubMed: 28856354]

5. Buechel FF; Pappas MJ: Ten-year evaluation of cementless Buechel-Pappas meniscal bearing total ankle replacement. Foot \& Ankle International. 2003; 24: 462-472. [PubMed: 12854666]

6. Concato J; Lawler EV; Lew RA, et al.: Observational methods in comparative effectiveness research. Am J Med. 2010; 123: 004.

7. Culler SD; Jevsevar DS; Shea KG, et al.: The Incremental Hospital Cost and Length-of-Stay Associated With Treating Adverse Events Among Medicare Beneficiaries Undergoing THA During Fiscal Year 2013. J Arthroplasty. 2016; 31: 42-48. [PubMed: 26318081]

8. Demetriades L; Strauss E; Gallina J: Osteoarthritis of the ankle. Clinical orthopaedics and related research. 1998; 349: 28-42.

9. Glazebrook M; Daniels T; Younger A, et al.: Comparison of health-related quality of life between patients with end-stage ankle and hip arthrosis. J Bone Joint Surg Am. 2008; 90: 499-505. [PubMed: 18310699]

10. Glazebrook MA; Arsenault K; Dunbar M: Evidence-based classification of complications in total ankle arthroplasty. Foot Ankle Int. 2009; 30: 945-949. [PubMed: 19796587]

11. Groll DL; To T; Bombardier C; Wright JG: The development of a comorbidity index with physical function as the outcome. J Clin Epidemiol. 2005; 58: 595-602. [PubMed: 15878473]

12. Harris N: Ankle arthritis. Current Orthopaedics. 2001; 15: 352-355.

13. Health, NIo: GUIDANCE ON REPORTING ADVERSE EVENTS TO INSTITUTIONAL REVIEW BOARDS FOR NIH-SUPPORTED MULTICENTER CLINICAL TRIALS. https:// grantsnihgov/grants/guide/noticefiles/not99-107html, 1999.

14. Healy WL; Della Valle CJ; Iorio R, et al.: Complications of total knee arthroplasty: standardized list and definitions of the Knee Society. Clin Orthop Relat Res. 2013; 471: 215-220. [PubMed: 22810157]

15. Hothorn T; Bretz F; Westfall P: Simultaneous inference in general parametric models. Biom J. 2008; 50: 346-363. [PubMed: 18481363]

16. Huch K; Kuettner KE; Dieppe P: Osteoarthritis in ankle and knee joints Seminars in arthritis and rheumatism, Elsevier, pg 667-674, 1997.

17. Kahl C; Cleland JA: Visual analogue scale, numeric pain rating scale and the McGill pain Questionnaire: an overview of psychometric properties. Physical Therapy Reviews. 2005; 10: 123128.

18. Kellgren JH; Lawrence JS: Radiological assessment of osteo-arthrosis. Ann Rheum Dis. 1957; 16 : 494-502. [PubMed: 13498604]

19. Kitsios GD; Dahabreh IJ; Abu Dabrh AM; Thaler DE; Kent DM: Patent foramen ovale closure and medical treatments for secondary stroke prevention: a systematic review of observational and randomized evidence. Stroke. 2012; 43: 422-431. [PubMed: 22180252]

20. Kivlan BR; Martin RL; Wukich DK: Responsiveness of the foot and ankle ability measure (FAAM) in individuals with diabetes. The Foot. 2011; 21: 84-87. [PubMed: 21550796] 
21. Kofoed H; Lundberg-Jensen A: Ankle arthroplasty in patients younger and older than 50 years: a prospective series with long-term follow-up. Foot \& ankle international. 1999; 20: 501-506. [PubMed: 10473061]

22. Krause FG; Di Silvestro M; Penner MJ, et al.: Inter- and intraobserver reliability of the COFAS end-stage ankle arthritis classification system. Foot Ankle Int. 2010; 31: 103-108. [PubMed: 20132745]

23. Lee MJ; Mohamed KMS; Kelly JC, et al.: Recording Adverse Events Following Joint Arthroplasty: Financial Implications and Validation of an Adverse Event Assessment Form. J Arthroplasty. 2017; 32: 2648-2654. [PubMed: 28629903]

24. Lenth RV: Least-Squares Means: The R Package lsmeans. Journal of Statistical Software. 2016; 69.

25. Martin RL; Irrgang JJ; Burdett RG; Conti SF; Van Swearingen JM: Evidence of validity for the Foot and Ankle Ability Measure (FAAM). Foot \& Ankle International. 2005; 26: 968-983. [PubMed: 16309613]

26. Martin RL; Stewart GW; Conti SF: Posttraumatic ankle arthritis: an update on conservative and surgical management. journal of orthopaedic \& sports physical therapy. 2007; 37: 253-259. [PubMed: 17549954]

27. Mercer J; Penner M; Wing K; Younger AS: Inconsistency in the Reporting of Adverse Events in Total Ankle Arthroplasty: A Systematic Review of the Literature. Foot Ankle Int. 2016; 37: 127136. [PubMed: 26445992]

28. Millstone DB; Perruccio AV; Badley EM; Rampersaud YR: Factors Associated with Adverse Events in Inpatient Elective Spine, Knee, and Hip Orthopaedic Surgery. J Bone Joint Surg Am. 2017; 99: 1365-1372. [PubMed: 28816896]

29. Pyevich MT; Saltzman CL; Callaghan JJ; Alvine FG: Total ankle arthroplasty: a unique design. Two to twelve-year follow-up. J Bone Joint Surg Am. 1998; 80: 1410-1420. [PubMed: 9801209]

30. Roukis TS; Bartel AF: Survivorship of First-, Second-, and Third-Generation Total Ankle Replacement Systems Primary and Revision Total Ankle Replacement, Springer, pg 15-23, 2016.

31. Saltzman CL; Amendola A; Anderson R, et al.: Surgeon training and complications in total ankle arthroplasty. Foot Ankle Int. 2003; 24: 514-518. [PubMed: 12854675]

32. Saltzman CL; Mann RA; Ahrens JE, et al.: Prospective controlled trial of STAR total ankle replacement versus ankle fusion: initial results. Foot Ankle Int. 2009; 30: 579-596. [PubMed: 19589303]

33. Sebastian AS; Polites SF; Glasgow AE, et al.: Current Quality Measurement Tools Are Insufficient to Assess Complications in Orthopedic Surgery. J Hand Surg Am. 2017; 42: 10-15 e11. [PubMed: 27889092]

34. SooHoo NF; Zingmond DS; Ko CY: Comparison of reoperation rates following ankle arthrodesis and total ankle arthroplasty. J Bone Joint Surg Am. 2007; 89: 2143-2149. [PubMed: 17908889]

35. Team, RDC: R: A language and environment for statistical computing R Foundation for Statistical Computing. Vienna, Austria, 2016.

36. Venables WN; Ripley BD: Tree-based methods Modern Applied Statistics with S. New York, Springer-Verlag, Inc., pg 251-270, 2002.

37. Voskuijl T; Hageman M; Ring D: Higher Charlson Comorbidity Index Scores are associated with readmission after orthopaedic surgery. Clin Orthop Relat Res. 2014; 472: 1638-1644. [PubMed: 24276857]

38. Wickham H: ggplot2: Elegant Graphics for Data Analysis, New York, Springer-Verlag, 2009.

39. Williamson A; Hoggart B: Pain: a review of three commonly used pain rating scales. J Clin Nurs. 2005; 14: 798-804. [PubMed: 16000093]

40. Younger AS; Glazebrook M; Veljkovic A, et al.: A Coding System for Reoperations Following Total Ankle Replacement and Ankle Arthrodesis. Foot Ankle Int. 2016; 37: 1157-1164. [PubMed: 27530987] 

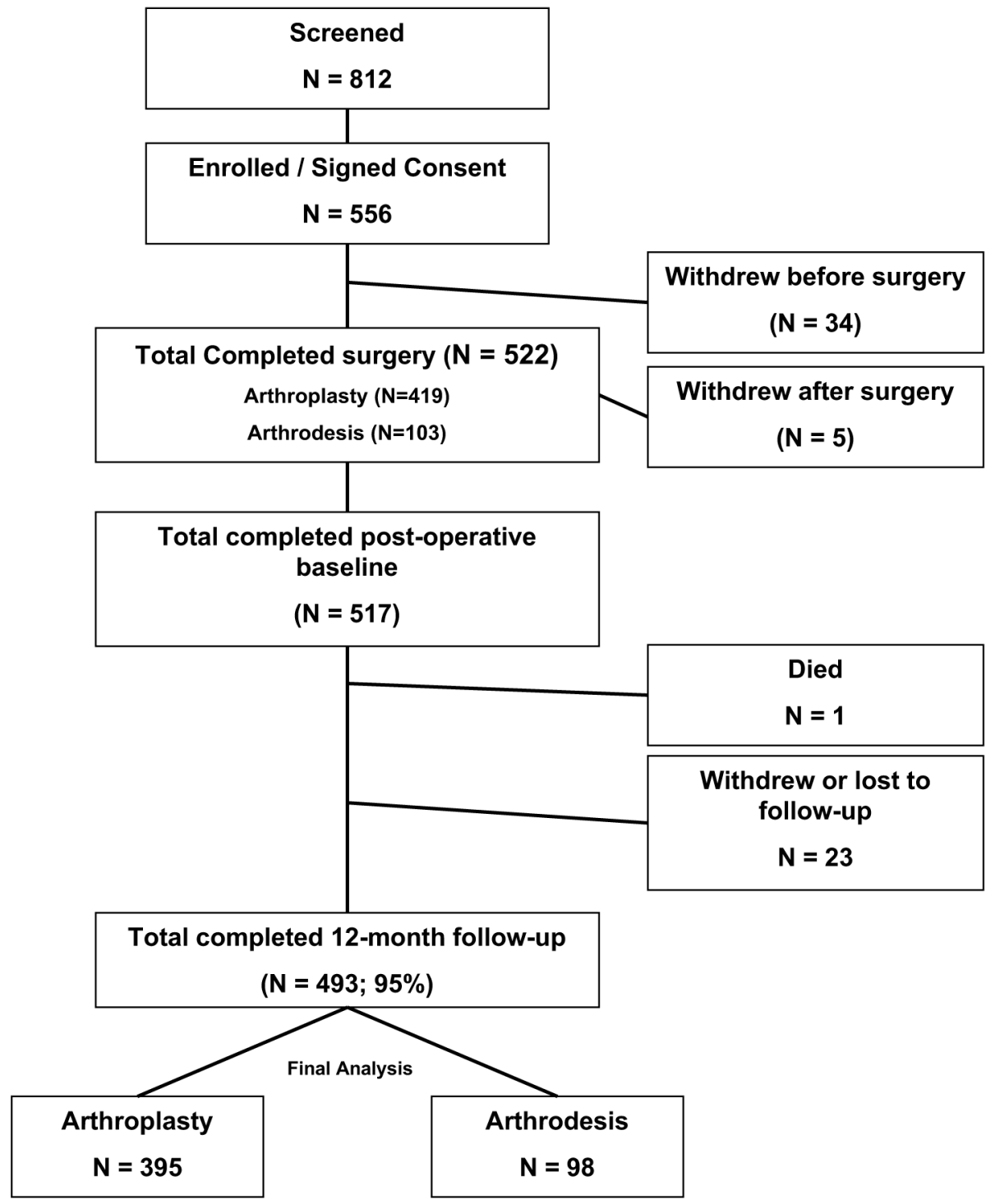

Figure 1:

Strobe diagram summarizing patients screened, enrolled, and those who completed 12month follow-up. 


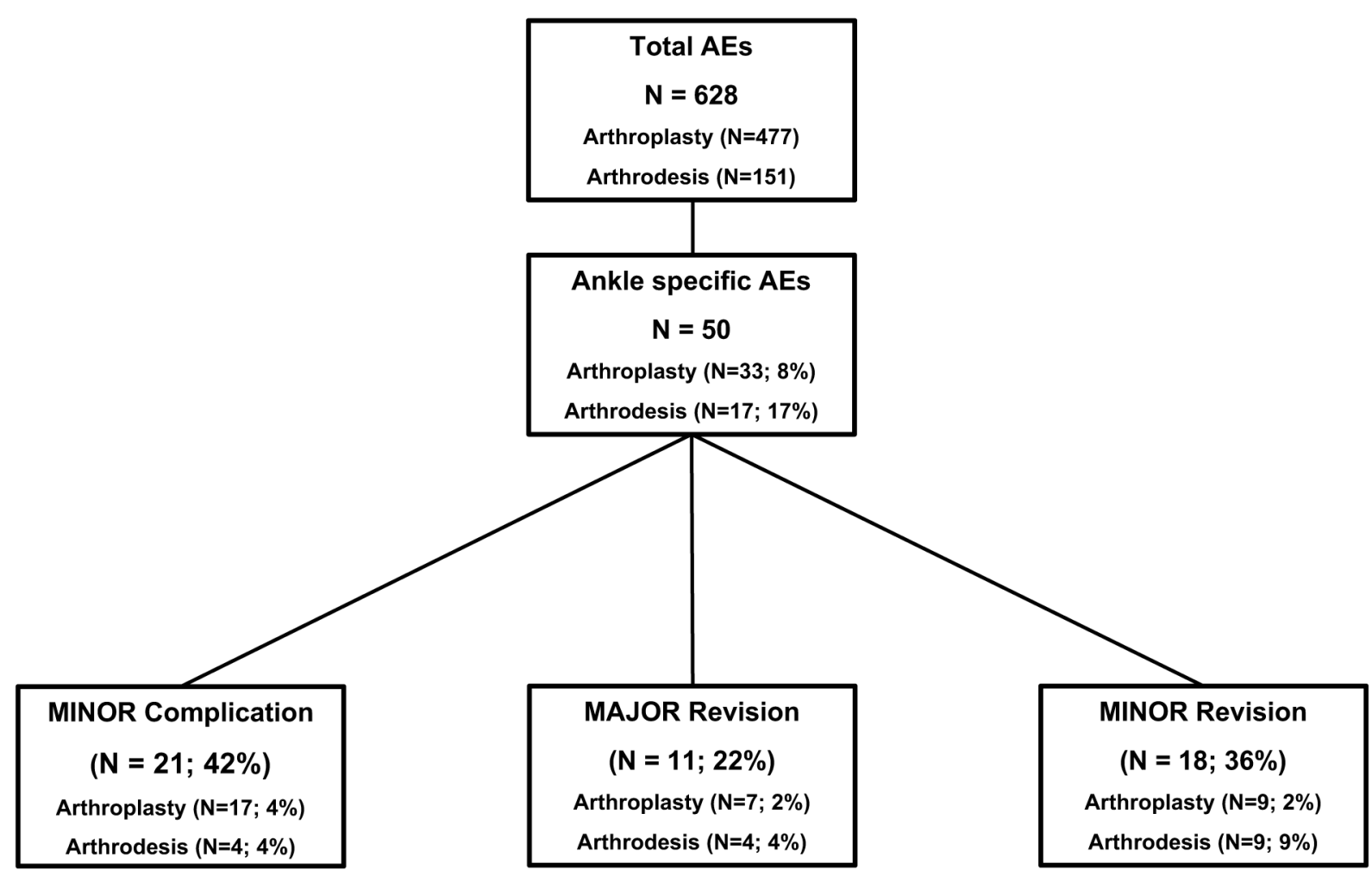

Figure 2:

Strobe diagram depicting the classification of adverse events and ankle specific complications. 
a)
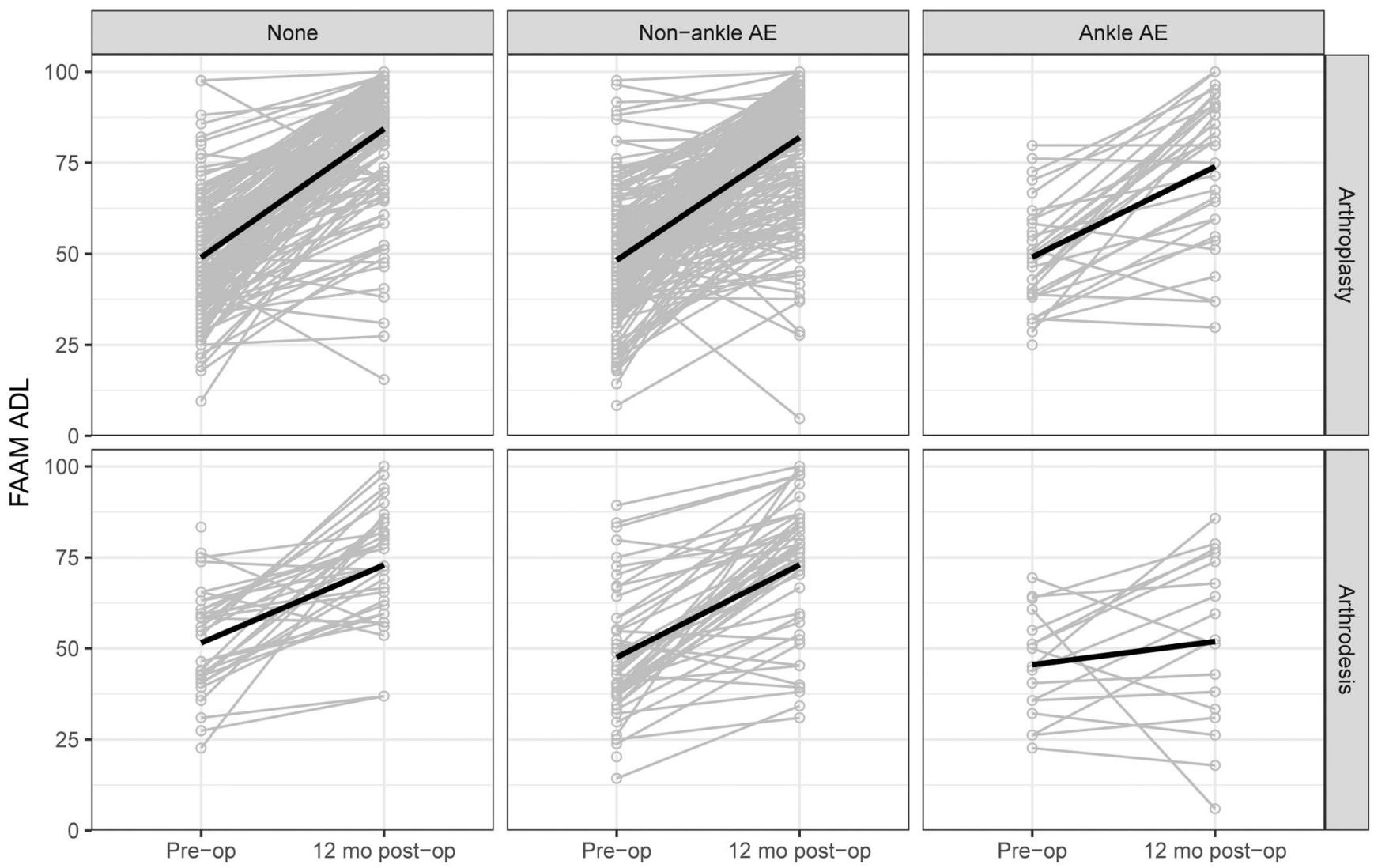

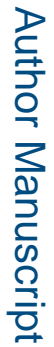
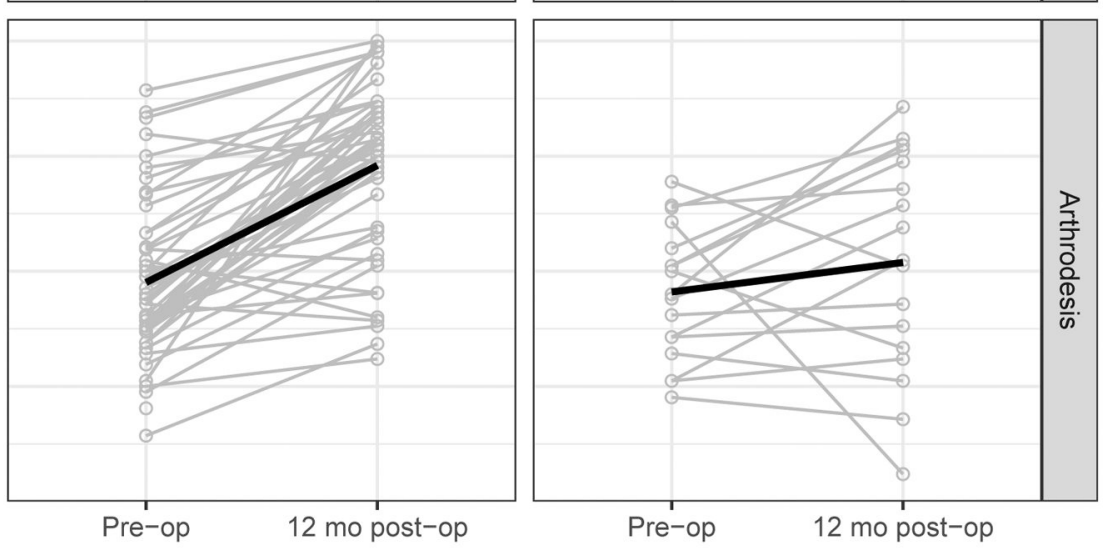

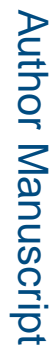

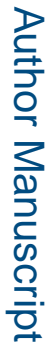

Foot Ankle Int. Author manuscript; available in PMC 2019 September 01. 
b)

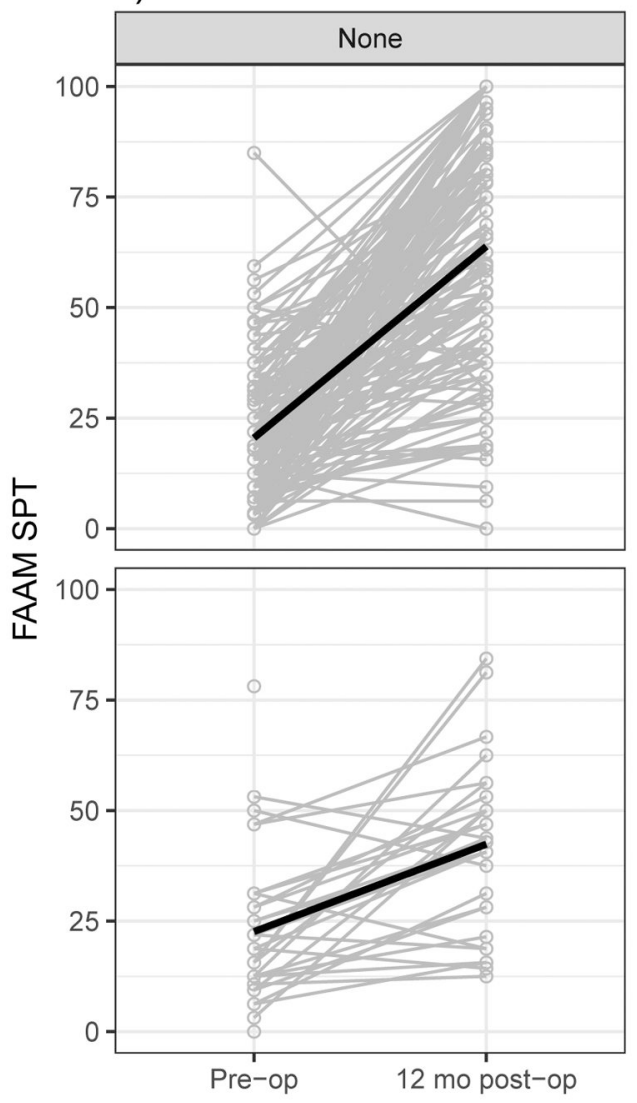

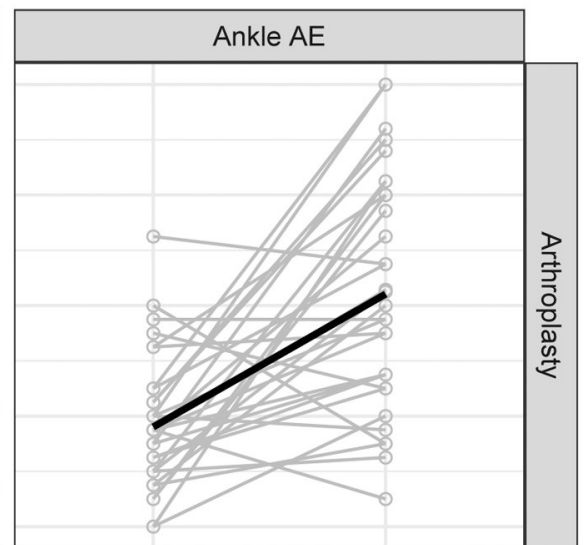
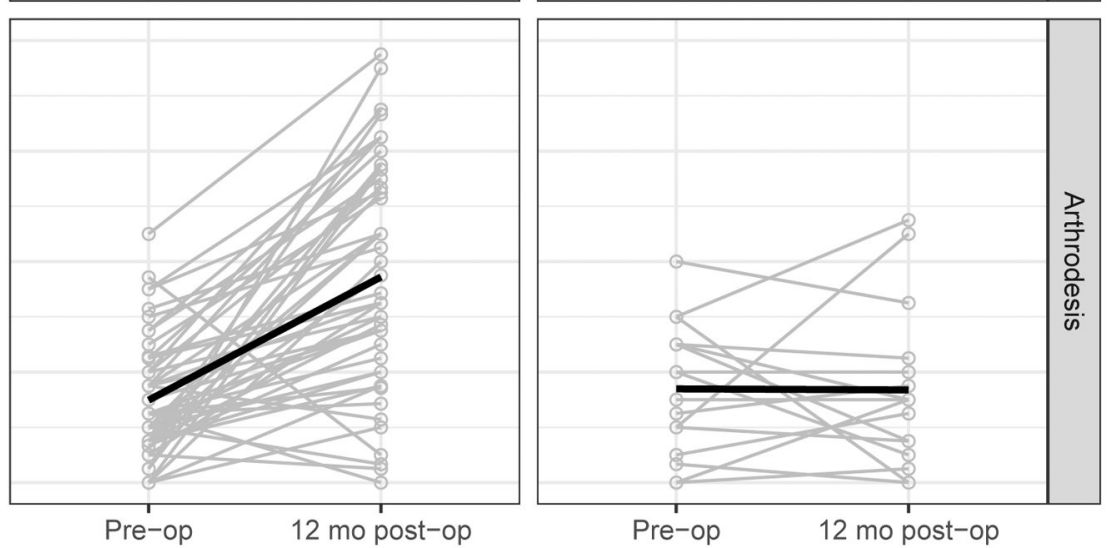

Figure 3:

ADL (a) and SPT (b) by study visit, surgery type and AE occurrence. Each line represents one patient's trajectory. Average lines were obtained using linear mixed effects regression of outcome on visit by surgery type interaction. 
Table 1:

Baseline characteristics comparing arthroplasty to arthrodesis participants.

\begin{tabular}{|c|c|c|c|c|}
\hline Characteristic & $\begin{array}{c}\text { Arthroplasty } \\
(\mathrm{N}=\mathbf{4 1 4})\end{array}$ & $\begin{array}{l}\text { Arthrodesis } \\
(\mathrm{N}=\mathbf{1 0 3})\end{array}$ & $\begin{array}{c}\text { P- } \\
\text { Value }\end{array}$ & $\begin{array}{l}\text { TOTAL } \\
(\mathbf{N}=517)\end{array}$ \\
\hline Gender (Male), $n(\%)$ & $237(57)$ & $61(59)$ & .66 & $298(58)$ \\
\hline Age, mean $\pm S D$ & $63.3 \pm 9.7$ & $54.2 \pm 12.7$ & $<.01$ & $61.4 \pm 10.9$ \\
\hline$B M I$, mean $\pm S D$ & $29.9 \pm 5.5$ & $33.1 \pm 7.2$ & $<.01$ & $30.5 \pm 6.0$ \\
\hline Race, $n(\%)$ & & & .78 & \\
\hline White/Caucasian & 403 (97) & $100(97)$ & & $503(97)$ \\
\hline Non-white & $11(3)$ & $3(3)$ & & $14(3)$ \\
\hline Marital Status (Married), n (\%) & $327(79)$ & $71(69)$ & .08 & $398(77)$ \\
\hline College graduate, $n(\%)$ & $246(59)$ & $58(56)$ & .53 & $304(59)$ \\
\hline Employment, $n(\%)$ & & & .01 & \\
\hline Employed & $193(47)$ & $58(56)$ & & $251(49)$ \\
\hline Unemployed/Retired & $221(53)$ & $44(43)^{*}$ & & $265(51)$ \\
\hline Income (More than \$75,001), n (\%) & $193(47)$ & $33(32)$ & $<.01$ & $226(46)$ \\
\hline Cause of ESAA, $n(\%)$ & & & .05 & \\
\hline Post-Traumatic & $213(52)$ & $70(68)$ & & $283(54)$ \\
\hline Recurrent Sprains & $53(13)$ & $10(10)$ & & $63(12)$ \\
\hline Degenerative & $71(17)$ & $10(10)$ & & $81(16)$ \\
\hline Instability & $50(12)$ & $6(6)$ & & $56(11)$ \\
\hline Misalignment & $16(4)$ & $3(3)$ & & $19(4)$ \\
\hline Other & $11(3)$ & $4(4)$ & & $15(3)$ \\
\hline Previous foot/ankle surgeries, $n(\%)$ & $237(57)$ & $77(75)$ & .01 & $314(61)$ \\
\hline Xrays - Severity of OA, $n(\%)$ & & & .13 & \\
\hline $0-1$ & $4(1)$ & $2(2)$ & & $6(1)$ \\
\hline 2 & $21(5)$ & $9(9)$ & & $30(6)$ \\
\hline 3 & $93(23)$ & $29(28)$ & & $122(24)$ \\
\hline 4 & $296(72)$ & $63(61)$ & & $359(69)$ \\
\hline \multicolumn{5}{|l|}{ Xrays, mean $\pm S D$} \\
\hline Alignment degrees & $8.7 \pm 8.8$ & $9.2 \pm 9.3$ & .64 & $8.8 \pm 8.9$ \\
\hline Subluxation & $16.4 \pm 18.6^{* *}$ & $13.5 \pm 17.8$ & .15 & $15.8 \pm 18.4$ \\
\hline \multicolumn{5}{|l|}{ Medical History/Comorbidities, $n$ (\%) } \\
\hline Osteoporosis & $43(10)$ & $5(5)$ & .08 & $48(9)$ \\
\hline Anxiety or Panic Disorder & $31(8)$ & $22(21)$ & $<.01$ & $53(10)$ \\
\hline Degenerative disc disease & $75(18)$ & $23(22)$ & .33 & $98(19)$ \\
\hline Functional Comorbidity Index, mean $\pm S D$ & $2.7 \pm 1.5$ & $3.4 \pm 2.1$ & $<.05$ & $2.9 \pm 1.7$ \\
\hline Current smoker, $n(\%)$ & $8(2)$ & $10(10)$ & $<.01$ & $18(4)$ \\
\hline Current alcohol use $\geq 6$ times weekly, $n(\%)$ & $61(15)$ & $11(11)$ & .19 & $72(14)$ \\
\hline
\end{tabular}




\section{Table 2:}

Mean ( \pm SE) preoperative functional outcomes and mean $( \pm$ SE, (95\% confidence intervals)) postoperative improvement at 12 months from pre-op by AE occurrence from linear mixed effects regression of functional outcome on AE status adjusted for differences in improvement by age, sex, BMI, FCI and surgical procedure *

\begin{tabular}{|c|c|c|c|c|c|c|c|c|c|}
\hline & \multicolumn{2}{|c|}{$\begin{array}{c}\text { None } \\
(n=193)\end{array}$} & \multicolumn{2}{|c|}{$\begin{array}{c}\text { Non-ankle } \\
(\mathbf{n}=\mathbf{2 7 8})\end{array}$} & \multicolumn{2}{|c|}{$\begin{array}{l}\text { Ankle } \\
(\mathbf{n}=50)\end{array}$} & \multicolumn{2}{|c|}{$\begin{array}{c}\text { Differences } \\
\text { in post-op change by } \\
\mathbf{A E} \text { group }\end{array}$} & \multirow[t]{2}{*}{ P-value } \\
\hline & Pre-op * & $\begin{array}{l}12 \text { mo } \\
\text { change }\end{array}$ & Pre-op* & $\begin{array}{l}12 \text { mo } \\
\text { change }\end{array}$ & Pre-op* & $\begin{array}{l}12 \text { mo } \\
\text { change }\end{array}$ & $\begin{array}{l}\text { Non- } \\
\text { ankle - } \\
\text { none }\end{array}$ & $\begin{array}{l}\text { Ankle - } \\
\text { none }\end{array}$ & \\
\hline $\mathrm{ADL}$ & $49.8 \pm 1.3$ & $\begin{array}{l}30.0 \pm 1.7 \\
(25.8,34.2) \\
\mathrm{p}<.001\end{array}$ & $48.7 \pm 1.2$ & $\begin{array}{l}28.9 \pm 1.5 \\
(25.2,32.6) \\
p<.001\end{array}$ & $48.9 \pm 2.3$ & $\begin{array}{l}17.2 \pm 3.0 \\
(9.8,24.7) \\
p<.001\end{array}$ & $\begin{array}{l}-1.1 \pm 1.9 \\
(-6.0,3.7) \\
p=.93\end{array}$ & $\begin{array}{l}-12.8 \pm 3.3 \\
(-21.0,-4.5) \\
p<.001\end{array}$ & $<.001$ \\
\hline $\mathrm{SPT}^{\dagger}$ & $21.4 \pm 1.7$ & $\begin{array}{l}34.4 \pm 2.3 \\
(28.5,40.3) \\
p<.001\end{array}$ & $20.6 \pm 1.5$ & $\begin{array}{l}32.6 \pm 2.0 \\
(27.5,37.6) \\
p<.001\end{array}$ & $22.9 \pm 3.0$ & $\begin{array}{l}17.8 \pm 4.1 \\
(7.5,28.0) \\
p<.001\end{array}$ & $\begin{array}{l}-1.8 \pm 2.7 \\
(-8.5,4.9) \\
\mathrm{p}=.90\end{array}$ & $\begin{array}{l}-16.6 \pm 4.5 \\
(-28.0,-5.2) \\
p=.001\end{array}$ & $<.001$ \\
\hline $\begin{array}{l}\mathrm{SF}-36 \\
\mathrm{PCS} *\end{array}$ & $36.0 \pm 0.7$ & $\begin{array}{l}11.1 \pm 0.8 \\
(9.1,13.1) \\
p<.001\end{array}$ & $34.7 \pm 0.6$ & $\begin{array}{l}10.7 \pm 0.7 \\
(9.0,12.5) \\
p<.001\end{array}$ & $33.4 \pm 1.2$ & $\begin{array}{l}7.6 \pm 4 \\
(4.0,1) \\
p<.001\end{array}$ & $\begin{array}{l}-0.4 \pm 0.9 \\
(-2.7,1.9) \\
p=.97\end{array}$ & $\begin{array}{l}-3.6 \pm 1.5 \\
(-7.4,0.3) \\
p=.084\end{array}$ & .064 \\
\hline $\begin{array}{l}\mathrm{SF}-36 \\
\mathrm{MCS}{ }^{*}\end{array}$ & $54.0 \pm 0.7$ & $\begin{array}{l}2.1 \pm 0.8 \\
(0.2,4.1) \\
p=.023\end{array}$ & $54.4 \pm 0.6$ & $\begin{array}{l}1.3 \pm 0.7 \\
(-0.4,2.9) \\
p=.21\end{array}$ & $55.4 \pm 1.2$ & $\begin{array}{l}-0.8 \pm 1.3 \\
(-4.2,2.5) \\
p=.92\end{array}$ & $\begin{array}{l}-0.9 \pm 0.9 \\
(-3.1,1.3) \\
p=.73\end{array}$ & $\begin{array}{l}-3.0 \pm 1.5 \\
(-6.7,0.8) \\
p=.17\end{array}$ & .13 \\
\hline Presentpain & $5.2 \pm 0.2$ & $\begin{array}{l}-3.8 \pm 0.3 \\
(-4.4,-3.2) \\
p<.001\end{array}$ & $5.3 \pm 0.2$ & $\begin{array}{l}-3.9 \pm 0.2 \\
(-4.4,-3.4) \\
p<.001\end{array}$ & $5.4 \pm 0.3$ & $\begin{array}{l}-3.4 \pm 0.4 \\
(-4.5,-2.3) \\
p<.001\end{array}$ & $\begin{array}{l}-0.1 \pm 0.3 \\
(-0.8,0.6) \\
p=.99\end{array}$ & $\begin{array}{l}0.4 \pm 0.5 \\
(-0.8,1.7) \\
p=.77\end{array}$ & .51 \\
\hline $\begin{array}{l}\text { Worst pain } \\
\text { past } 6 \\
\text { months }\end{array}$ & $8.3 \pm 0.2$ & $\begin{array}{l}-4.7 \pm 0.2 \\
(-5.4,-4.1) \\
p<.001\end{array}$ & $8.5 \pm 0.2$ & $\begin{array}{l}-4.7 \pm 0.2 \\
(-5.2,-4.2) \\
p<.001\end{array}$ & $8.5 \pm 0.3$ & $\begin{array}{l}-3.0 \pm 0.4 \\
(-4.1,-2.0) \\
p<.001\end{array}$ & $\begin{array}{l}0.1 \pm 0.3 \\
(-0.6,0.8) \\
p=1.0\end{array}$ & $\begin{array}{l}1.7 \pm 0.5 \\
(0.5,2.9) \\
p=.002\end{array}$ & $<.001$ \\
\hline
\end{tabular}

Independent co-variates (along with AE status) were age, sex, BMI and FCI as modeled as both

main effects and as interactions terms with study visit. Estimates presented are averaged over

mean age, BMI, FCI and levels of sex and surgical procedure

*** Omni

Omnibus hypothesis test for differences in 12 month change by AE status

One patient with no AEs had missing SPT at both visits.

${ }^{*}$ One patient with no AEs and one patient with a non-ankle AD had missing SF 36 scores 